\title{
Systematic Thinking on University Service-learning
}

\author{
Lu Dan ${ }^{1, ~ a, ~ D u a n ~ J i n g y a n ~}{ }^{2, b}$ \\ ${ }^{1}$ School of Public Finance and Management, Yunnan University of Finance and Economics, Kunming, \\ China \\ ${ }^{2}$ International Business School, Yunnan University of Finance and Economics, Kunming, China \\ a yufejennyludan@126.com, ${ }^{\text {b } 20025859 @ q q . c o m ~}$
}

Keywords: Higher education; Service-learning; Connotation; Methods

\begin{abstract}
Service-learning is a kind of educational experience and a teaching method, which combine community service with academic course to gain rich practical experience and understanding of academic content by the way of experiential learning. Service-learning set students as the main body of education, which combines the theory with practice to improve the understanding of theoretical knowledge and training work skills in practice. It has wide value in rich and perfect higher education quality assurance system. Some Chinese universities have made the relevant exploration, but the theoretical research is still relatively weak. This paper sorted out the connotation of service-learning, and summarized models, characteristics and principles of service-learning and its implementation.
\end{abstract}

\section{Introduction}

Service-learning provides the experiential practice platform for students, which guides students to combine academic skills with social demand by service-learning program. Service-learning not only provides multiple learning channels for students, but also can gain the first hand information to understand social demands. It can help students to understand the real social status. Besides, it can also help students to develop many skills, such as social, emotional and cross-cultural abilities, Professional and citizen participation skills, and integrating into the local community better. Service-learning is a philosophy. It focuses on the human development, life goals and social vision. It also encourages people to serve others reciprocally, and to develop their abilities. Compare with the traditional education model, service-learning has some advantages. American universities emphasize service-learning program on meanings and roles of the training innovative talents process, which take variety of patterns to build the platform for the students. Students improve themselves by participating the service-learning program in the platform.

\section{The Connotation of Service-learning}

The concept of service-learning originated in the United States, which has widely used in all kinds of American education institutions since the middle of 1980s.

The National Commission of on Service-Learning believes that "Service-Learning is a teaching method, which integrates community service with academic research to enrich learning, cultivate civic responsibility, and strengthen community well-being.”[1]

The National and Community Service Committee thought that service-learning is a kind of experiential education. "Students participate actual requirement service activates to learn, which organized by universities and communities cooperation in this experiential education. Service-learning should combine with academic courses, and provides time to consider, discuss, and write about what they did in service activities for students. It also provides opportunities for students to practice their daily life related knowledge and skills in actual environment. Besides, service-learning expand the learning of students outside classrooms and within communities, and cultivate students care about the others feelings." [2] 
No matter abroad or in domestic, scholars agree that service-learning is a form of experiential education, which meets needs of communities to promote students achievement and develop their practical abilities. Reflection and interaction are the core of service-learning.

\section{The Model of Service-learning}

\subsection{One-off and Short-term Service-learning}

One-off and short-term service-learning refers to organize students to participate activities, which will help them to general understand their communities. Service-learning as a kind of model used to guide students to take part in service-learning program in some American universities. These forms of service-learning include whole university activities, courses related service-learning activities, major oriented activities, and student union or group activities.

\subsection{Continuous After-school Service-learning}

Continuous after-school service-learning have different types, such as service-learning activities of cultivate leadership skills, service oriented service-learning activities, service-earning activities in dormitories, service-learning activities of the college students' association, and sports service-learning activities.

\subsection{Service Learning in the Course}

Both one-time or short-term service learning, and continuous service learning after class, are nothing more than to provide a practical experience for students, and to further play to the role of service learning, you must learn to service combined with academic learning, will service learning into the curriculum, can help students with the knowledge situation, explore the different definitions and good for a different interpretation of the social problems, questioning the purpose and function of knowledge, to find meaning of multilayered.

\subsection{Centralized Service-learning}

Concentration of service-learning means that students use spend more than 10 hours a week for service experience accumulating during a certain period, such as a semester or a summer holiday. Besides, students live in the familiar surroundings for their daily lives.

\subsection{Service-learning in Depth}

The deep experience not only provides working opportunities for students in communities, but also let students to lives in communities. The experience accumulating can be one week, one summer holiday, one semester or even longer. In this case, students take the unfamiliar culture as their life background.

\section{The Characteristics and Principles of Service-learning}

\subsection{The Characteristics of Service-learning}

\subsubsection{The Diversity}

The diversity of service-learning shows characteristics as study object, study results, the learning process, and learning results. [3] Objectives of service-learning are not only the students and teachers, but also include schools and communities. The communication between students and teachers and the community practice experience formed the learning process of service-learning. The diversity results of service-learning are reflective, which is reflected in the core of service-learning. Reflecting students' individual knowledge, skills and learning practice are useful for finding their strengths and weaknesses, perfecting and adapting educational requirements. Community residents will change their impression of college students by community practice activities. 


\subsubsection{Reflective}

Reflection is the core of service-learning. Without reflection, service-learning has no difference with community service. Through community activities, students not only can find local problems by themselves, and focus others more, but also can learn from others, feel happiness from others. These will help students to perfect their own personalities. As participants of service-learning, students and teachers achieve goals of studying, servicing, reflecting, and restudying by reflective conclusions of writing diaries, experiential and class reports.

\subsubsection{Reciprocity}

Service-learning is the process of interaction and cooperation between people, which is the better model to cultivate students' interpersonal skills. Students can get following abilities by two-way interactive understanding, such as making objective comments for their abilities, recognizing the society comprehensively and objectively, making comments for issues understanding, and increasing the consciousness of participating social public affairs. [4]

\subsubsection{Social}

Service-learning integrates social services into university courses, and uses learned knowledge to support the service process, which provides opportunities for students to understand the social situation. Students learn communicating, cooperating with others to improve abilities of finding and shoveling problems by participating service activities. In addition, service-learning takes promoting community development and improving students' socialization as its goals and duties. It also improves students' social adaptation by developing their abilities of social communication and responsibility.

\subsection{The Principle of Service-learning}

\subsubsection{Combining Service with Learning}

The basis of service-learning is to combine social practice with study in social practice, which can promote students to apply new knowledge during service process. After reinforcing and expanding class learned knowledge, service-learning will help students to improve their practice abilities by actively reflecting learned knowledge during service process. Therefore, service-learning is popularly recommended by educational workers. [5]

\subsubsection{Compatibility between Community and School}

Service-learning is a learning method that emphasizes the combination of community services and school teaching. This method needs community to provide practice areas for students, so school needs to contact with the community before students carrying on the service learning.

\subsubsection{The Combination of Courses, Service and Reflection}

The nature of service-learning is combining school courses and service. Service-learning can improve students' knowledge, skills and abilities by reflecting their community service activities, and let them cultivate their consciousness of citizens, social responsibility, and cooperation spirit.

\section{Implement the Different Stages of Service-learning}

\subsection{Preparation Stage}

Preparation stage includes preparation, planning and training. The successful factor of service-learning is preparation. The preparation includes identifying service items, partners, places and field study. Preparation needs to consider requirements of communities and students' hobbies, and evaluate available community resources around schools and community problems that need to resolve. Cooperative partners need to communicate with each other to make sure that each part can gain common benefits and identify roles and responsibilities for partners. From identifying, implementing, completing to evaluating projects, each staged of the continuing process needs to be 
detailed. Involving students into the planning making is helpful for combining school courses with community services to satisfy demand. After made the planning, school need to tell students details of practice activities, and help them to understand service objectives, duties, learning objectives, requirements, and individual roles and responsibilities.

\subsection{Implementation Stage}

According to confirmed plan, it is necessary to adjust and fine turning when carry out the service-learning in implementation stage. As the mentor and inspirer, teachers need to assist students to combine service activities with school courses, and help them to deal with the difficulties in service-learning with reasonable guidance and motivation. Schools should strengthen the contact with communities to provide campus and community resources as the good learning environment for students at the stage. Schools need to keep tight relationship and higher agreement with communities, because the social service practices need supports of related communities.

\subsection{Reflecting Stage}

The reflecting stage of service-learning includes vertical earlier stage reflection, concurrent reflection, and reflection after service. It also includes horizontal students and teachers reflections. Reflections are often carried out by group discussions, role playing, blogs or dairies, and dialogue recording. The reflecting depth of students determines different achievements from the same service-learning activities. Both students and teachers should involve into reflections for focal points in this stage. The meaning of teachers' reflection is to achieve goals of teaching planning, results evaluation, and improving teaching abilities. The meaning of students' reflection is to gain following experiences, such as experience summarizing by own accumulation, recognizing the meaning of service-learning, finding relationship between their majors and real lives.

\subsection{Celebrate Stage}

Celebrating is a stage of harvesting and sharing success of service-learning. Celebratory activities are participated by relevant people of service-learning. Based on sharing and understanding, service-learning establishes a happy, tolerance, rational space for recognizing achievements, inspire confidence, obtaining acceptance. The celebration can be combined with the evaluation, and let students receive thank-you notes, badges and certificates to promote the further development of service-learning.

\subsection{Evaluation Stage}

The evaluation can be formal or informal, qualitative or quantitative, formative assessment or summative evaluation, self-assessment or others' assessments. Teachers should provide experience exchanging platform for students, so they can learn from each other in this stage. [6] This stage applies evaluation indexes and methods to analyze and assess practices of students' service-learning performance. These analysis and assessment not only can record and assess students' service standards, but also can be a means to improve student learning.

\section{Conclusion}

The service-earning program emphasizes service activities participation of students and after activities communication and reflection to develop students' independent thinking abilities. It will help students to clarify experiential goals, contents and process, and helps them internalize service-earning experience as their own abilities. Service-learning takes social services as a part of courses, and applies learning contents in service process, which provides the wide understanding of the social situation for students. Students learned communicating and cooperating with others by participating service activities, and also improves abilities of finding and solving problems.

Besides, service-learning takes promoting community development as its goal, and improving the students' socialization as its duties. Service-learning also pays attention to develop the students' ability of social communication and responsibility to improve their social adaptation abilities. 
Chinese colleges and universities can learn from service-learning method. Domestic colleges and universities need consider different situations of universities, majors and social environments to design relevant social practice activities, which will help students to obtain following achievements, such as being able to work in the real environments, fully understanding major knowledge, enhancing consciousness of social service, improving quality of college students, and adapting society better.

\section{Acknowledgements}

This research was financially supported by the scientific research funds of Yunnan Province Department of Education "research on the effective path of undergraduate social practice from the perspective of service learning” (2017ZZX005).

\section{References}

[1] Randa Mahasneh, Aisheh Tawalbeh, "Integrating service learning in Jordanian higher education,” Innovations in Education and Teaching International, V49, pp. 415-425, 2012.

[2] B. Naidoo, B. Devnarain, "Service learning: Connecting higher education and civil society Are we meeting the challenge?” South African Journal of Higher Education, V23, pp.935-952, 2009.

[3] Ji Jiao, Wu Xinchun, Qing Zixin, Informal learning: learn the growth points of scientific research, Journal of Beijing Normal University (Social Sciences), 2017(1):74-82.

[4] Yan Chang, Service-learning: A change in quality education, Data of Culture and Education, 2015(16):138-139.

[5] Liao Kuo, Liu Longchang, Research on the cultivation of practical ability of college students under the perspective of service learning, Ideological and Political Education Research, 2013,29(06):134-135.

[6] Cui Suiqing, American service-learning: features, principles, and procedures, Ningxia Educational Research, 2008(3):14-19. 